\title{
Physics Identity Promotes Alternative Careers for First-Generation College Students in Engineering
}

\author{
Dina Verdín, Purdue University, West Lafayette (College of Engineering)
}

Dina Verdín is a Ph.D. student in Engineering Education and M.S. student in Industrial Engineering at Purdue University. She completed her undergraduate degree in Industrial and Systems Engineering at San José State University. Dina is a 2016 recipient of the National Science Foundation's Graduate Research Fellowship (GRF). Her research interest focuses on first-generation college students, specifically around changing deficit base paradigms by providing asset base perspectives for understanding this community.

\section{Dr. Allison Godwin, Purdue University, West Lafayette (College of Engineering)}

Allison Godwin, Ph.D. is an Assistant Professor of Engineering Education at Purdue University. Her research focuses what factors influence diverse students to choose engineering and stay in engineering through their careers and how different experiences within the practice and culture of engineering foster or hinder belongingness and identity development. Dr. Godwin graduated from Clemson University with a B.S. in Chemical Engineering and Ph.D. in Engineering and Science Education. She is the recipient of a 2014 American Society for Engineering Education (ASEE) Educational Research and Methods Division Apprentice Faculty Grant. She has also been recognized for the synergy of research and teaching as an invited participant of the 2016 National Academy of Engineering Frontiers of Engineering Education Symposium and 2016 New Faculty Fellow for the Frontiers in Engineering Education Annual Conference. She also was an NSF Graduate Research Fellow for her work on female empowerment in engineering which won the National Association for Research in Science Teaching 2015 Outstanding Doctoral Research Award. 


\title{
Physics Identity Promotes Alternative Careers for First- Generation College Student in Engineering
}

\begin{abstract}
This research study explored first-generation college students' in engineering post-graduation career intentions based on responses to a quantitative survey. In this paper, we answer the following research questions: 1) How do first-generation college students' measures of physics, mathematics, and engineering identity constructs differ compared to non-first-generation college students? and 2) How does a physics identity influence first-generation college student's choice of an engineering major and career aspirations? The data came from the Intersectionality of Nonnormative Identities in the Cultures of Engineering (InIce) survey. InIce was completed by 2,916 first-year engineering college students enrolled in four institutions across the United States-72\% non-first-generation college students, $20 \%$ first-generation college students, and $8 \%$ non-reporting students. The survey measured attitudinal profiles of belongingness in engineering, identity constructs (i.e., engineering, physics, and mathematics), affective measures, and demographic information.
\end{abstract}

Previous studies quantitatively and qualitatively measured and validated the constructs that make up math identity, physics identity and engineering identity (i.e., interest in the subject, recognition by others, and beliefs about one's performance/competence) for predicting engineering choice. To answer the first research question, a Welch's t-test was used to compare the averages of firstgeneration college students and non-first-generation college students on overall measures of mathematics, physics, and engineering identity as well as the constructs of interest, recognition, and performance/competence in each subject area. This t-test was selected because it corrects unequal variance within the two populations. To answer the second research question, we used multiple linear regression to predict the choices of STEM and non-stem majors using measures of identity, affective factors, and first-generation college student status. Results from the first analysis demonstrate that first-generation college students entered engineering with a high sense of engineering identity, particularly in the performance/competence and interest constructs. Regression results showed that first-generation college students' physics identity positively predicted choice of a non-STEM career; that is, first-generation college students with high physics identity were more interested in non-STEM careers (e.g., non-profit/non-government organization and medicine/health). This work highlights that first-generation college students may have different career pathway intentions and motivations in studying engineering during college.

\section{Introduction and Motivation}

Engineering culture shapes who students become. The culture of engineering ... "is not simply training in a prescribed set of appropriate, academic courses, but is enculturation into a wellestablished system of practices, meanings, and beliefs" (p. 218) ${ }^{1}$. Engineering is a community of practice where students aspiring to become members must acquire the cultural norms, values, and behaviors appropriate for this community. Such norms may encompass a students' knowing what it takes to act and be recognized as a competent member of the community ${ }^{2}$. Competence is one aspect of enculturating within a community of practice. Students' enculturation into the engineering community of practice requires that educators understand how students associate with, withdraw from, and/or negotiate the cultural norms of this community. Once in an engineering community of practice, students begin to form their identities as engineers. These identities are 
"important outcomes of participation in communities of practice" (p. 57) . "Identity construction is the process of thinking about oneself as an engineer, performing an engineer self, and ultimately being thought of as an engineer" (p. 273-274, italics in original ${ }^{4}$. Additionally, identity is shaped by context and is, thus, intimately tied to learning within the engineering classroom ${ }^{5}$. Participation in an engineering community of practice not only supports the development of students' identity, it also means that students are not entirely free to develop any type of engineering identity, rather they are guided by "larger and more pervasive meanings of [engineering] identity derived from sociohistorical legacies of [engineering]; and historical and political meanings of being" an

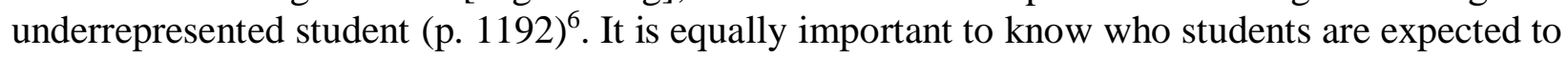
be, that is, how are traditional engineering practices are emphasizing a certain way of being that may promote particular career pathways differentially for diverse students.

Identity development has important practical outcomes including academic and personal development ${ }^{7-10}$, retention $^{11-13}$, and professional formation ${ }^{4,14,15}$. In this paper, we examine another student outcome, career pathways. Research shows that women and students of color choose an engineering industry career after college less of then than their peers ${ }^{16-18}$. However, little is known about how first-generation college students (FGCS) compare to their peers on career outcomes and how these outcomes might be affected by the ways in which FGCS see themselves as the kind of people who engage in particular STEM subjects. Our research examines these relationships to understand affective attributes that might be developed in undergraduate engineering education to promote more diverse engineers entering industrial jobs and highlight needs for the engineering context to support students in STEM identity development.

\section{First-Generation College Students}

First-generation college students (FGCS) are defined as a college student who comes from a family where neither parents have had a college or post-secondary experience, while a non-firstgeneration college student (non-FGCS) is defined as a student who reported at least one of their parents completing some post-secondary education ${ }^{19,20}$. The classification of FGCS in the studies are consistent in that they are not relegated to racial/ethnic minorities. Studies do not explicitly affirm FGCS are of a certain racial/ethnic minority, rather studies suggest that they are "more likely to be" African-American and/or Latino/a $\mathrm{a}^{21,22}$. Evidence suggesting a disproportionate amount of FGCS come from underrepresented groups is further articulated in the report First in My Family (p. 6) ${ }^{22}$. First-generation college students have multiple intersecting identities i.e., race/ethnicity, LGBTQ+, low-socioeconomic status, and disability status to name a few, that are less privileged in an engineering context. The purpose of recognizing the intersectional identities of FGCS is to draw awareness to the complexities of this population and to acknowledge that our analysis only points to one aspect of students' social identity. We have explored intersectional identities of first-generation college students in a previous study ${ }^{23}$. In this paper, we do not unpack the multiple intersections of students' social identities due to a small sample size of FGCS.

Literature on career aspirations of FGCS' and STEM identities is scant. Studies on FGCS often focus on postsecondary success and access, mostly taking a deficit approach by pointing out poor academic preparation ${ }^{24-28}$, negative experiences ${ }^{29}$, limited support $^{22,30}$, and barriers towards their future careers ${ }^{31}$. Our prior work began to highlight FGCS' career aspirations, while not yet focusing on STEM identities. Using data from a study of over 50 different 2- and 4-year colleges across the U.S. of students enrolled in first-year English courses, results demonstrated that on 
average FGCS, had a greater interest in engineering careers, a career as a math/science teacher, and a greater interest in a career in physics ${ }^{32}$. Additionally, when asked about expectations for their future career, FGCS reported a higher level of interests in supervising others, inventing/designing things, developing new knowledge and skills, doing hands-on work, and applying math and science, than their non-FGCS peers ${ }^{32}$. This study was a first step towards building a profile of FGCS, specifically those in engineering, outside the deficit base narrative that has dominated the literature. Similarly, other literature of first-generation college students, while not specific to engineering, found that FGCS reported similar degree aspirations as their non-FGCS peers, that is, bachelor's degree through doctoral or professional degree) $)^{30}$. While the study reported significant levels of barriers for FGCS, it is worth emphasizing that despite the academic and social barriers reported in the study, FGCS career aspirations were not deterred ${ }^{30}$.

We acknowledge that FGCS face many barriers towards achieving a higher education. In this paper, we decided to center our investigations on students' perceptions of themselves, their identities, with the goal of finding leverage points to empower FGCS toward careers in engineering. It is equally important to understand FGCS' perceptions of themselves as someone that could be or do a particular STEM-subject, as it is to understand barriers to access and success. This study takes the former approach as we seek to provide a narrative about FGCS that is often overlooked or untold. We focused on how FGCS identified themselves rather than allowing the school systems to define them through non-personal measures (i.e., GPA, SAT/ACT scores, or years to degree completion).

\section{Theoretical Framework}

In this study, we used instruments with strong validity evidence to measure students' physics, mathematics, and engineering identities. These items were developed from a rich background of identities studies, mostly qualitative, and theoretical sources ${ }^{3,6,33-35}$. In this section, we will describe how constructs of physics, mathematics, and engineering identity were developed. Our definition of identity, what it means to be an engineer, comes from $\mathrm{Gee}^{33}$, who pushed for identity research in the education space, coining identity as being recognized as a certain "kind of person" (p. 99). Gee presented four aspects of identity including 1) who we are, 2) one's position in society, 3) recognition by others through interaction, and 4) one's experiences within affinity groups. Building on Gee's theory of identity, Carlone and Johnson's ${ }^{6}$ science identity theoretical framework was created as a model of three interrelated facets-performance, competence, and recognition. Carlone and Johnson ${ }^{6}$ defined performance as "relevant scientific practices (e.g., ways of talking and using tools); competence as "knowledge and understanding of science content;" and recognition as "recognizing oneself and getting recognized by others as a "science person"” (p. $1191)^{6}$. These dimensions of identity are interwoven and are essential to the enactment of particular STEM identities. To be a particular "kind of person," one must make visible one's competence through performance, and be recognized by others as credible.

Expanding on the work of Carlone and Johnson's three dimensions of science identity and Gee's ${ }^{33}$ external recognition of identity, Hazari and colleagues ${ }^{35}$ reframed the approach of understanding role identity to include an additional aspect, interest in the subject. Interest was added to the identity framework because it was subsequently correlated to students' choice of a physics major" ${ }^{35}$ Similarly, it was postulated that "when studying students' choice of field, the development of their interests is of critical relevance ... the link between the development of 
interest and career choice is mediated by changes in self-perceptions (and identity; p. 979) ${ }^{35}$. Thus, these science identity constructs (i.e., recognition, performance, and competence), were amended to also include interest in a physics context ${ }^{35,36}$. Upon use, Hazari et al. ${ }^{35}$ found that students early on in their undergraduate careers could not distinguish between performance and competence beliefs. Students responded similarly to survey items measuring performance and competence, and therefore, these questions were combined into a single construct ${ }^{36}$. Similar measures from science and physics were created for mathematics identity ${ }^{37,38}$. In structural equation modeling of these constructs, students' performance/competence beliefs were weak direct predictors of identifying as the type of person that can do a particular STEM subject ${ }^{36,39}$. However, when these beliefs were mediated by students' perceptions of interest and recognition, they were a positive predictor of identities in physics and math ${ }^{40}$. These results indicate the performance/competence beliefs or feeling that one can understand and do well in a particular subject are not enough to have a STEM identity. Students must also be interested and feel recognized by others to hold these identities.

From these prior studies, mathematics and physics identity were positive predictors of choice of engineering career at the beginning of college $\mathrm{e}^{37,40}$. However, an instrument for directly measuring students' engineering identity did not exist. A more recent study of post-secondary engineering students documented the development and validity testing of an engineering identity measure using the constructs of interest, recognition, performance/competence ${ }^{41}$. These measures of students' mathematics, physics, and engineering role identities have a rich history of use and can provide useful ways of understanding how particular students may or may not see themselves as the type of people that can do engineering. From prior research, these attitudes can also influence their career pathways. Using these identity constructs in the context of physics, engineering, and mathematics we thus sought to address the following two research questions:

1) How do first-generation college students' (FGCS) measures of physics, mathematics, and engineering identities constructs differ compared to non-first-generation college students (non-FGCS)?

2) How does a physics, mathematics, or engineering identity influence first-generation college student's (FGCS) choice of an engineering major and career aspirations?

\section{Methods}

The data analyzed in this study were from the Intersectionality of Non-normative Identities and Cultures of Engineering (InIce) survey administered in the Fall of 2015 at three land-grant institutions and one Hispanic-Serving Institution (HSI) in different regions of the United States. The InIce survey was designed to measure several factors related to how students felt about their place in the engineering community, their attitudes towards engineering, and their perceptions about their future in engineering. The target population for this study was first-year engineering students and overall participants $N=2,916$ completed the survey during the first two weeks of classes. The survey was administered via paper format to ensure high response rates and was later digitized for further analysis.

The InIce survey consisted of multiple survey items used to measure students' attitudinal profiles consisting of belongingness in engineering, STEM identities (i.e., engineering, physics, and math), other affective measures, and demographic information as well as students' career goals and choice of engineering major. All attitudinal responses were measured on a seven-point anchored numeric scales $(0=$ "strongly disagree" to $6=$ "strongly agree"). The outcomes of engineering major, 
engineering career, STEM careers, and non-STEM careers were all measured on an anchored scale (0 - "not at all likely" and 6 - "extremely likely") where students responded with the likelihood that they would choose a major or career in a list of options. First-generation college students (FGCS) status was coded as a binary variable with $1=$ FGCS and $0=$ non-FGCS. If students responded to a question about their parent/guardian level of education for either parent/guardian with "bachelor's degree" or "master's degree or higher," they were coded as $0=$ non-FGCS. If they responded with all parent/guardian level of education "less than a high school diploma," "high school diploma/GED," or "some college or associate/trade degree," they were coded as 1 = FGCS. Students that did not report parent's education level were eliminated from the study.

In this paper, we focused only on factors pertaining to engineering, physics, and math identity constructs (i.e., interest, recognition, performance/ competence), choice of engineering major, and career choice. The questions measures of identity followed a similar question format with the particular subject name changed. Table 1 shows the questions for physics identity grouped by construct. The factor structure for these items has been verified and published previously ${ }^{41,42}$. A composite score for each construct was calculated by averaging each students' response on the items measuring interest, recognition, and performance/competence for each subject for this analysis. We used a Welch's t-test for group comparisons and multiple regression for predicting choice of engineering major and career. A Welch's t-test was selected because it does not make assumptions of homogeneity of variances, that is, it allows for group sample sizes to be unequal ${ }^{43,44}$. Multiple regression was selected in order to predict choice of major and career accounting for various predictor variables and the interactions among predictor variables that "produce an effect on the outcome $Y$ [choice of major and career choice] that is different from the sum of the effect of the individual predictor" ( p. 255) ${ }^{45}$. All analyses were conducted using the statistical software, $\mathrm{R}^{46}$.

Table 1. Items developed to measure physics identity

\begin{tabular}{|l|l|}
\hline Constructs & Statement \\
\hline Interest & $\begin{array}{l}\text { Q7Phys_f = I am interested in learning more about physics } \\
\text { Q7Phys_g = I enjoy learning physics } \\
\text { Q7Phys_h = I find fulfillment in doing physics }\end{array}$ \\
\hline Recognition & $\begin{array}{l}\text { Q7Phys_b = My parents see me as a physics person } \\
\text { Q7Phys_c = My instructors see me as a physics person }\end{array}$ \\
& $\begin{array}{l}\text { Q7Phys_d = My peers see me as a physics person } \\
\text { Q7Phys_e = I've had experiences in which I was recognized as a physics person }\end{array}$ \\
& Q7Phys_m = Others ask me for help in physics \\
\hline Performance/ & $\begin{array}{l}\text { Q7Phys_i = I am confident that I can understand physics in class } \\
\text { Competence }\end{array}$ \\
& $\begin{array}{l}\text { Q7Phys_j = I am confident that I can understand physics outside of class } \\
\text { Q7Phys_k = I can do well on exams in physics }\end{array}$ \\
& Q7Phys_I = I understand concepts I have studied in physics \\
& Q7Phys_n = I can overcome setbacks in physics
\end{tabular}

\section{Results}

From the overall $N=2,916$ participants, $72 \%\left(\mathrm{n}_{1}=2,092\right)$ were non-first-generation college students (non-FGCS), that is, students reported parent(s)/guardian(s) completed a 'bachelor's degree" or "master's degree or higher;" $20 \%\left(\mathrm{n}_{2}=596\right)$ were first-generation college students (FGCS), that is, students reported both parents/guardians obtained "less than a high school diploma," "high school diploma/GED," or "some college or associate/trade degree;" and $8 \%\left(\mathrm{n}_{3}=\right.$ 
228) did not report their parent's educational background. Students that did not report parent's education level were eliminated from the study. First, we tested the internal consistency of the three constructs in each of the subject-related identity measures (i.e., performance/competence, interest, and recognition). Analysis yielded Cronbach alpha values of $\alpha=0.89$ for physics interest, $\alpha=0.89$ for physics recognition, $\alpha=0.92$ for physics performance/competence, $\alpha=0.89$ for engineering interest, $\alpha=0.83$ for engineering recognition, $\alpha=0.88$ for engineering performance/competence, $\alpha=0.88$ for mathematics interest, $\alpha=0.86$ for mathematics recognition, and $\alpha=0.90$ for mathematics performance/competence - see Table 2 at the end of the paper.

Then, we compared FGCS and non-FGCS on overall measures of physics, mathematics, and engineering identity using Welch's t-tests - see Table 3. The questions that measured these overall identities consisted of a question that asked students to respond to the statement, "I see myself as (a physics person/a math person/an engineer)" for each subject area. The results indicated that FGCS' overall engineering identity $\left(M_{F G C S}=4.86\right.$; Cohen's $\left.d=0.13 ; p<0.001\right)$ and mathematics identity $\left(M_{F G C S}=4.89\right.$; Cohen's $\left.d=0.10 ; p<0.05\right)$ measures are significantly greater than nonFGCS. Overall physics identity was greater for non-FGCS $\left(M_{n o n-F G C S}=4.30\right.$; Cohen's $d=0.17 ; p<$ 0.001) than for FGCS.

Table 3. FGCS and Non-FGCS Group Differences on Identity Constructs.

\begin{tabular}{|c|c|c|c|c|}
\hline Constructs & $\begin{array}{r}\text { Average for } \\
\text { First-Generation }\end{array}$ & $\begin{array}{l}\text { Average for Non- } \\
\text { First-Generation }\end{array}$ & Significance $^{\S}$ & $\begin{array}{l}\text { Effect Size } \\
(\text { Cohen's } d \text { ) }\end{array}$ \\
\hline Physics Identity & 4.20 & 4.30 & $* * *$ & 0.17 \\
\hline Interest & 4.58 & 4.69 & - & 0.08 \\
\hline Recognition & 3.51 & 3.88 & $* * *$ & 0.26 \\
\hline $\begin{array}{l}\text { Performance/ } \\
\text { Competence }\end{array}$ & 4.24 & 4.32 & - & 0.07 \\
\hline Engineering Identity & 4.86 & 4.75 & $* *$ & 0.13 \\
\hline Interest & 5.38 & 5.21 & $* * *$ & 0.19 \\
\hline Recognition & 4.53 & 4.50 & - & 0.17 \\
\hline $\begin{array}{l}\text { Performance/ } \\
\text { Competence }\end{array}$ & 4.65 & 4.55 & $*$ & 0.11 \\
\hline Mathematics Identity & 4.89 & 4.79 & $*$ & 0.10 \\
\hline Interest & 4.96 & 4.82 & $*$ & 0.12 \\
\hline Recognition & 4.81 & 4.76 & - & 0.05 \\
\hline $\begin{array}{c}\text { Performance/ } \\
\text { Competence }\end{array}$ & 4.88 & 4.79 & $*$ & 0.10 \\
\hline
\end{tabular}

We also compared FGCS and non-FGCS on the constructs of each identity instrument. For the constructs of engineering identity, FGCS reported statistically significantly greater interest $\left(M_{F G C S}\right.$ $=5.38$; Cohen's $d=0.19 ; p<0.001)$ and performance/competence $\left(M_{F G C S}=4.65\right.$; Cohen's $d=$ $0.11 ; p<0.05)$. Similarly, for the mathematics identity constructs, FGCS reported statistically significantly greater interest $\left(M_{F G C S}=4.96\right.$; Cohen's $\left.d=0.12 ; p<0.05\right)$ and performance/competence $\left(M_{F G C S}=4.65\right.$; Cohen's $\left.d=0.10 ; p<0.05\right)$. Non-FGCS' indicated a significantly greater physics recognition $\left(M_{n o n-F G C S}=3.88\right.$; Cohen's $\left.d=0.26 ; p<0.001\right)$ than FGCS. All other comparisons were non-significant. 
Next, we examined how students' physics, mathematics, or engineering identity influenced FGCS' choice of an engineering major and career aspirations. We conducted multiple linear regression analysis to predict the relationship between the outcomes: choice of engineering major, choice of STEM, and choice of non-STEM careers using measures of each subject-related identities and first-generation college student status. The three models predicting the outcomes of interest were analyzed separately and, thus, will be reported separately.

For predicting choice of an engineering major, a multiple linear regression was conducted using engineering, physics, and mathematics identity, between first-generation college student status, and the interaction between first-generation college student status and subject-related identities as independent variables. In predicting engineering choice of major there was a significant main effect of engineering identity, $\beta=-0.08, p<0.001$; mathematics identity, $\beta=0.06, p<0.05$, and a significant interaction between physics identity and first-generation college student status $\beta=$ $0.13, p<0.05$ - see Table 4. Predicting choice of an engineering major revealed that measures of engineering identity negatively predicted $(p<0.01)$ engineering choice of major holding mathematics and physics identity constant. Mathematics identity was a positive predictor ( $p<$ 0.05) of engineering major choice. Whereas physics identity alone did not show statistical significance in predicting choice of an engineering major, the interaction effect between firstgeneration college student status and physics identity revealed a positive prediction of engineering choice of major $(p<0.05)$. This interaction effect indicates that being a FGCS and having a higher physics identity increases the likelihood of choosing an engineering major over non-FGCS. We acknowledge that the variance explained in the outcome, $R^{2}=0.01$, is small and many other factors affect choice of an engineering major.

Table 4. Summary of Regression Analysis for Predicting Engineering Choice of Major

\begin{tabular}{|c|c|c|c|}
\hline & Estimate & Standard Error & $\begin{array}{r}\text { Standard } \\
\text { Coefficient }(\boldsymbol{\beta})\end{array}$ \\
\hline (Intercept) & 0.18 & 0.05 & $* * *$ \\
\hline Engineering Identity & -0.03 & 0.01 & $-0.08 * *$ \\
\hline Physics Identity & -0.01 & 0.01 & -0.04 \\
\hline Math Identity & 0.02 & 0.01 & $0.06^{*}$ \\
\hline First-generation College Student & 0.05 & 0.10 & 0.07 \\
\hline $\begin{array}{l}\text { Engineering Identity * First-generation } \\
\text { College Student }\end{array}$ & -0.02 & 0.02 & -0.06 \\
\hline $\begin{array}{l}\text { Physics Identity * First-generation College } \\
\text { Student }\end{array}$ & 0.03 & 0.01 & $0.13^{*}$ \\
\hline $\begin{array}{l}\text { Math Identity * First-generation -College } \\
\text { Student }\end{array}$ & -0.01 & 0.02 & -0.04 \\
\hline$R^{2}$ & & 0.010 & \\
\hline$F$ & & $3.28 * * *$ & \\
\hline
\end{tabular}

Similarly, for predicting engineering industry career choice-Table 5, a multiple linear regression was performed using measures of subject-related identities (i.e., engineering, physics, and 
mathematics identity), first-generation college student status, and the interaction between firstgeneration college student status and subject-related identities as independent variables. These predictors explained much more of the variance in students' intentions to choose a career in an engineering industry with an $R^{2}$ of 0.19 . In predicting engineering industry career choice there was significant main effects of engineering identity, $\beta=0.35, p<0.001$; physics identity, $\beta=.07, p<$ 0.01 and mathematics identity, $\beta=0.08, p<0.001$. There were also significant interactions between engineering identity and first-generation college student status $\beta=0.11, p<0.05$ and physics identity and first-generation college student status $\beta=-0.13, p<0.01$.

Table 5. Summary of Regression Analysis for Predicting Engineering Industry Career Choice

\begin{tabular}{|c|c|c|c|}
\hline Items & Estimate & Standard Error & $\begin{array}{l}\text { Standard Coefficient } \\
(\beta)\end{array}$ \\
\hline (Intercept) & 2.49 & 0.14 & $* * *$ \\
\hline Engineering Identity & 0.41 & 0.03 & $0.35 * * *$ \\
\hline Physics Identity & 0.05 & 0.02 & $0.07 * *$ \\
\hline Math Identity & 0.08 & 0.03 & $0.08 * * *$ \\
\hline First-generation College Student & -0.01 & 0.30 & 0.01 \\
\hline $\begin{array}{l}\text { Engineering Identity * First-generation } \\
\text { College Student }\end{array}$ & 0.13 & 0.06 & $0.11 *$ \\
\hline $\begin{array}{l}\text { Physics Identity * First-generation } \\
\text { College Student }\end{array}$ & -0.11 & 0.04 & $-0.13 * *$ \\
\hline $\begin{array}{l}\text { Math Identity * First-generation College } \\
\text { Student }\end{array}$ & 0.01 & 0.06 & -0.01 \\
\hline$R^{2}$ & & 0.19 & \\
\hline$F$ & & $78.73 * * *$ & \\
\hline
\end{tabular}

This regression analysis demonstrates that all three subject-related identities statistically significantly predict students' intentions of pursuing an engineering industry career. However, the estimate for engineering identity is almost five times as large as physics or mathematics identities in predicting the outcome. For FGCS, there was a significant positive interaction effect with engineering identity $(p<0.05)$. This interaction indicates that students who are FGCS are even more likely to choose and engineering industry career that their non-FGCS peers. Similarly, for the first-generation college student population, we see a negative interaction with physics identity $(p<0.01)$ indicating that FGCS with higher physics identity are less likely to choose an engineering industry career.

A regression analysis of non-engineering industry career choices is shown in Table 6. We predicted two non-engineering, STEM-related careers: medicine/health and non-profit or non-government organization. In predicting a medicine/health career choice, there was a significant main effect of physics identity, $\beta=-0.12, p<0.01$ and mathematics identity, $\beta=0.05, p<0.05$. There was also a significant interaction between physics identity and first-generation college student status $\beta=$ $0.15, p<0.01$. This result indicates that FGCS with higher physics identities are more likely that 
non-FGCS to choose a medicine/health career. In the analysis predicting non-profit/nongovernment organization career choice, there was significant main effects for physics identity, $\beta$ $=-0.07, p<0.01$; mathematics identity, $\beta=0.05, p<0.05$; and first-generation college student status $\beta=-0.33, p<0.05$. We also found a significant interaction between physics identity and first-generation college student status $\beta=0.23, p<0.001$. These results indicate that FGCS are, on average, less likely to be interested in entering a non-profit or non-government organization from engineering than non-FGCS. However, the interaction effect between physics identity and first-generation college student status indicates that FGCS with a high physics identity are more likely than non-FGCS to choose a career in a non-profit or non-government sector, but there is still an overall negative association for all engineering students. In both regressions, the $R^{2}$ values are small indicating that not much of the variance in the outcomes of interest were explained by the identity and FGCS status; however, these analyses allow us to directly compare STEM identities and FGCS in the career outcomes of interest.

Finally, we examined non-STEM outcomes in K-12 and higher education careers. In predicting career choice in the K-12 sector, there was a significant main effect of engineering identity, $\beta=$ $0.11, p<0.001$; physics identity, $\beta=-0.06, p<0.001$; and mathematics identity, $\beta=0.06, p<$ 0.05 . There was also a significant interaction between physics identity and first-generation college student status $\beta=0.12, p<0.05$. This interaction effect indicates that even though a high physics identity for the entire population is a negative predictor of a K-12 career interest, being a firstgeneration college student makes a student significantly more likely to have a long-term career interest in K-12 education. Lastly, a multiple linear regression analysis was conducted to predict choice of Academia (Higher Education) career. In predicting career choice in the Higher Education sector there was a significant main effect of mathematics identity, $\beta=0.14, p<0.001$ and a significant interaction between physics identity and first-generation college student status $\beta=0.12$, $p<0.05$. Physics identity along with being a first-generation college student, again, significantly predicted a higher likelihood of an interest in pursuing a career in higher education. In both regressions, the $R^{2}$ values are small indicating that not much of the variance in the outcomes of interest were explained by the identity and first-generation college student status; however, these analyses allow us to directly compare particular STEM identities and FGCS in the career outcomes of interest. 
Table 6. Summary of Regression Analysis for Predicting Medicine/Health Career Choice

\begin{tabular}{|c|c|c|c|c|c|c|}
\hline & \multicolumn{3}{|c|}{ a. Medicine/Health } & \multicolumn{3}{|c|}{ b. Non-Profit/Non-Government Organization } \\
\hline & B & SE B & $\beta$ & B & SE B & $\beta$ \\
\hline (Intercept) & 3.17 & 0.32 & $* * *$ & 2.23 & 0.27 & $* * *$ \\
\hline Engineering Identity & -0.13 & 0.07 & -0.05 & -0.10 & 0.06 & -0.05 \\
\hline Physics Identity & -0.21 & 0.05 & $-0.12 * *$ & -0.10 & 0.04 & $-0.07 * *$ \\
\hline Math Identity & 0.12 & 0.06 & $0.05^{*}$ & 0.09 & 0.05 & $0.05^{*}$ \\
\hline First-generation College Student & -0.93 & 0.68 & -0.19 & -1.35 & 0.57 & $-0.33^{*}$ \\
\hline Engineering Identity * First-generation College Student & 0.08 & 0.14 & 0.03 & 0.11 & 0.12 & 0.06 \\
\hline Physics Identity * First-generation College Student & 0.25 & 0.10 & $0.15^{* *}$ & 0.34 & 0.08 & $0.23 * * *$ \\
\hline Math Identity * First-generation College Student & -0.13 & 0.13 & -0.06 & -0.16 & 0.11 & -0.08 \\
\hline$\overline{R^{2}}$ & \multicolumn{3}{|c|}{0.02} & \multicolumn{3}{|c|}{0.02} \\
\hline$F$ & \multicolumn{3}{|c|}{$5.35^{* * * *}$} & \multicolumn{3}{|c|}{$4.93 * * *$} \\
\hline
\end{tabular}

* significance less than $0.05, * *$ significance less than 0.01 , and $* * *$ significance less than 0.001 
Table 7. Summary of Regression Analysis for Predicting Career Choice in Education

\begin{tabular}{|c|c|c|c|c|c|c|}
\hline & \multicolumn{3}{|c|}{ c. K-12 Education } & \multicolumn{3}{|c|}{ d. Academia (Higher Education) } \\
\hline & $\mathrm{B}$ & SE B & $\beta$ & $\mathrm{B}$ & SE B & $\beta$ \\
\hline (Intercept) & 1.65 & 0.21 & $* * *$ & 1.08 & 0.29 & $* * *$ \\
\hline Engineering Identity & -0.18 & 0.05 & $-0.11 * * *$ & -0.05 & 0.06 & -0.02 \\
\hline Physics Identity & -0.07 & 0.03 & $-0.06 * * *$ & 0.02 & 0.04 & 0.01 \\
\hline Math Identity & 0.09 & 0.04 & $0.06^{*}$ & 0.29 & 0.05 & $0.14 * * *$ \\
\hline First-generation College Student & -0.35 & 0.46 & $-0.11 *$ & -0.33 & 0.63 & -0.07 \\
\hline Engineering Identity $*$ First-generation College Student & 0.03 & 0.10 & 0.02 & -0.10 & 0.14 & -0.04 \\
\hline Physics Identity * First-generation College Student & 0.14 & 0.06 & $0.12 *$ & 0.19 & 0.09 & $0.12 *$ \\
\hline Math Identity * First-generation College Student & -0.06 & 0.09 & -0.04 & -0.01 & 0.12 & -0.01 \\
\hline$R^{2}$ & & 0.02 & & & 0.02 & \\
\hline$F$ & & $5.10 * * *$ & & & $7.49 * * *$ & \\
\hline
\end{tabular}

* significance less than $0.05, * *$ significance less than 0.01 , and $* * *$ significance less than 0.001 


\section{Discussion}

Our analysis suggests that on average, first-generation college students (FGCS) hold higher overall engineering identities $(p<0.001)$ than their non-first-generation college student (non-FGCS) peers. Further unpacking the constructs of engineering identity, we see that FGCS, on average ( $p$ $<0.001)$, are more interested in engineering than their peers. This interest in engineering is in response to questions asking, "I find fulfillment in doing engineering," "I enjoy learning engineering," and "I am interested in learning more about engineering," which may indicate that FGCS enter engineering with increased motivation to learn more about engineering topics. Interest has been associated with "intrinsically motivated behaviors because people seem to adopt those behaviors out of interest ... theories of human motivation have referred to people as being intrinsically motivated when they are freely doing what interests them" (p. 45) ${ }^{47}$. Research in science and engineering has also found that students' interest ("I am interested in learning more about engineering"), motivation ("I enjoy learning engineering"), and beliefs about themselves ("I find fulfillment in doing engineering") have a significant influence on persistence and participation ${ }^{35,37,48}$. Another study found that “... students leaving engineering reported that other majors were more interesting ... or that they found a more appealing career option outside of science and engineering ...," while our study is suggesting that FGCS at the start of their college trajectory are entering engineering with greater interest than their counterparts (p. 919) ${ }^{49}$. In addition, we see that FGCS measures of performance/competence in engineering are moderately higher $(p<0.05)$ than their non-FGCS peers. Indicating that, on average, FGCS enter engineering with higher confidence in understanding engineering, feeling like they can perform well on exams than their non-first-generation college student peers. First-generation college students' high selfreported measures of performance/competence is directly related to their self-efficacy and perception of themselves in relation to their chosen field, in this case engineering ${ }^{35}$. The importance of students' self-confidence and self-efficacy for persisting in science and engineering has been further articulated in a literature review by Geisinger and Raman ${ }^{49}$. This study examined literature on engineering students' attrition, while not explicitly focused on FGCS, it highlighted factors for why engineering students leave the field. One factor was lack of self-confidence and self-efficacy. Additional literature on self-confidence validates the claim that students leave engineering and science fields due to low confidence ${ }^{50,51}$ and perceived efficacy ${ }^{52,53}$. Our findings emphasize the strengths that FGCS bring with them into the engineering classroom including higher interest in engineering and mathematics as well as more confidence in their ability to succeed in engineering.

For mathematics identity, we see that FGCS, on average, had moderately higher overall measures $(p<0.05)$, as well as higher measures of interest and performance/competence $(p<0.05)$ compared to their non-first-generation college student peers. In a prior study, it was found that students' mathematics identity was an important factor for predicting engineering career choice ${ }^{37}$. However, in the same study by Cass and colleagues ${ }^{37}$, after controlling for the effect of SAT/ACT math scores, as these are known, to some extent, to account for actual math proficiency, students with high performance/competence beliefs were more likely to pick a STEM discipline outside of engineering. Our findings indicate that FGCS have higher interest and beliefs in their ability to succeed in mathematics. Often FGCS are represented as being less academically prepared that non-FGCS ${ }^{22}$. One hypothesis may be that these results are a product of a filter that only accepts the most exceptional students from first-generation college student applicant pool or only the most talented FGCS even apply to engineering programs in the first place. Another equally likely 
hypothesis may be that FGCS matriculating in engineering programs have had lived experiences that they saw mirrored in the engineering field. The findings none the less demonstrate that FGCS may be even more motivated to study engineering-related topics than their peers and provides a rationale for tying FGCS' interests and attitudes to engineering classes. One way to continue to foster FGCS' interest and motivation to study engineering is to use their lived experiences as a way to scaffold engineering concepts ${ }^{29,54,55}$.

Our group comparison also showed significantly higher overall physics identity $(p<0.001)$ for non-FGCS. Within the constructs of physics identity, we found that recognition (by parents, instructors, peers, and experiences where students felt recognized as a physics person) was significantly higher for non-FGCS than FGCS $(p<0.001)$. However, there were no statistically significant differences in averages on physics interest of physics performance/competence beliefs for non-FGCS and FGCS. Examining the subject-related identities and the constructs collectively, we see that FGCS, on average, report moderately higher levels of engineering and mathematics identity measures, while non-FGCS reported much higher levels of physics identity. More striking is the contrast between being recognized as a physics person for non-FGCS and the lack of recognition in any of the subjects for FGCS. Literature suggests that of the three constructs for physics identity, "the largest effect on students' physics identity ... comes from recognition by others" (p. 96) ${ }^{56}$. Additionally, we know from Godwin and colleagues ${ }^{40}$ that performance/competence beliefs alone, for both physics and mathematics, negatively predict choice of an engineering career. The authors of that study conclude that "performance/competence beliefs must also be present with interest and recognition beliefs to predict students' subject-related identities" (p. 327). The authors posit that the relationship between performance/competence beliefs implied that "[s]tudents who are recognized before they feel competent may not internalize the recognition, and very often teachers do not recognize students who are not excelling in their classrooms" (p. 327). These studies point to the importance of recognition for students, but in our work, we find that FGCS report feeling recognized much less often than their peers. These results provide opportunities for building FGCS' identities in an out of the classroom by providing engineering experiences that tie to prior experience and recognizing multiple answers and backgrounds as valid within the classroom.

When analyzing how FGCS' physics, mathematics, and engineering identity influence career aspirations, regression results revealed a positive interaction among FGCS and physics identity for non-engineering industry related careers and choice of engineering major. A research study using the same subject-related identity constructs ${ }^{40}$ found that mathematics and physics identities are important for predicting engineering choice at the beginning of college. Our analysis also supports and furthers these findings. We also showed that physics identity is a strong predictor of choice of engineering industry career. However, when we interact the dichotomous variable FGCS with each of the subject-related identities, we see a negative effect with physics identity $(p<0.01)$, positive interaction with engineering identity $(p<0.05)$, and no significance with mathematics identityTable 5. Indicating that for the first-generation college student population, mathematics identity has no influence in predicting a career in engineering industry, while having a high physics identity negatively predicts FGCS' pursuit of a career in engineering industry. Taken together with the results from the other regression analyses conducted for non-engineering, STEM-related careers (Table 6) and educational career pathways (Table 7), our results indicate the FGCS with higher 


\section{physics identities are more likely to choose engineering as a stepping stone to other career pathways.}

These results have implications for how engineering courses are taught, especially for FGCS. Our analysis suggests that FGCS may have alternative career plans or long-term goals and motivation as non-FGCS for studying engineering. Providing opportunities to engage in other activities that are more consistent with long-term goals may provide ways to connect FGCS' identities in STEM subjects with their long term goals ${ }^{57}$. Stronger connections to current tasks and long-term goals can provide higher motivation and identity salience in engineering ${ }^{58,59}$. These positive effects may increase students' desires to remain in engineering majors. Additionally, providing opportunities for FGCS to have experiences in which they feel recognized as a STEM person, in their secondary and post-secondary courses, may provide ways to open pathways into engineering for FGCS.

\section{Limitations and Future Work}

Our data is cross-sectional. Therefore, we cannot make causal inferences on why FGCS' physics identity predicts careers in engineering industry, non-profit/non-government organization, K-12 education or higher education; however, this analysis starts a conversation on alternative career paths first-generation college students in engineering may take. Additionally, we cannot claim our results are nationally representative as data were gathered from only four institutions.

We acknowledge that our analysis reveals only one point in time, engineering students in their first semester of college, thus we cannot make inferences about students who pursued careers outside of an engineering industry. Our findings only make causal predictions based on measures of subject-related identities. Further analysis using qualitative methods would allow us to understand why FGCS who matriculate in engineering at the start of college may be more interested in future careers outside of engineering using nationally representative data. Our future work also involves examining differences in how FGCS may respond to or interpret the quantitative measures used in this analysis.

\section{Conclusions}

Our work examined differences in engineering first-generation college students (FGCS) and nonfirst-generation college students (non-FGCS) responses on quantitative measures of physics, mathematics, and engineering identities. We found that FGCS had higher overall measures of engineering and mathematics identities than their peers. We also found that FGCS had higher interest and performance/competence beliefs in mathematics and engineering than non-FGCS. These results provide asset-based ways to discuss attitudinal strengths that FGCS bring into the engineering classroom. We also found either no significant differences in non-FGCS and FGCS on physics identity measures or higher averages for non-FGCS on overall physics identity and physics recognition. Physics may provide a context to improve FGCS' beliefs about the type of person that they can be and ways to engage in engineering. Previous research has shown that physics identity is more important than mathematics identity in engineering choice, and interventions to develop FGCS' physics identities prior to college may increase enrollment in engineering. Finally, we found that FGCS with higher physics identities were more likely to choose career pathways outside of engineering. These findings have implications for how FGCS are taught in engineering classes. 


\section{Acknowledgements}

This work was supported by the National Science Foundation through grant 1428689 and the National Science Foundation Graduate Research Fellowship. The opinions expressed are those of the author and do not necessarily represent those of the NSF. The authors wish to thank the participants of the surveys and the Intersectionality of Non-normative Identities in the Cultures of Engineering (InIce) research groups including Lisa Benson, Adam Kirn, Geoff Potvin, Hank Boone, Jacqueline Doyle, and Monique Ross, for their support in collecting this data 
Table 2. Physics, Engineering, and Math Identity Survey Items

Students were asked to what extent to you agree or disagree with the following statements VALUES: 0 through 6 (rating scale); $0=$ "strongly disagree", $6=$ "strongly agree"

Physics Interest $\alpha=\mathbf{0 . 8 9}$

Q7Phys_f = I am interested in learning more about PHYSICS

Q7Phys_g = I enjoy learning PHYSICS

Q7Phys_h = I find fulfillment in doing PHYSICS

\section{Physics Recognition $\alpha=\mathbf{0 . 8 9}$}

Q7Phys_b = My parents see me as a PHYSICS person

Q7Phys_c $=$ My instructors see me as a PHYSICS person

Q7Phys_d = My peers see me as a PHYSICS person

Q7Phys_e = I've had experiences in which I was recognized as a PHYSICS person

Q7Phys_m = Others ask me for help in PHYSICS

Physics Performance/Competence $\alpha=0.92$

Q7Phys_i = I am confident that I can understand PHYSICS in class

Q7Phys_ $\mathrm{j}$ = I am confident that I can understand PHYSICS outside of class

Q7Phys_k = I can do well on exams in PHYSICS

Q7Phys_1 = I understand concepts I have studied in PHYSICS

Q7Phys_n = I can overcome setbacks in PHYSICS

Engineering Interest $\alpha=\mathbf{0 . 8 9}$

Q8Eng_h $=\mathrm{I}$ am interested in learning more about engineering

Q8Eng_i = I enjoy learning engineering

Q8Eng_ $\mathrm{j}$ = I find fulfillment in doing engineering

Engineering Recognition $\alpha=\mathbf{0 . 8 3}$

Q8Eng_d = My parents see me as an engineer

Q8Eng_e = My instructors see me as an engineer

Q8Eng_f = My peers see me as an engineer

Engineering Performance/Competence $\alpha=\mathbf{0 . 8 8}$

Q8Eng_k = I am confident that I can understand engineering in class

Q8Eng_l = I am confident that I can understand engineering outside of class

Q8Eng_m = I can do well on exams in engineering

Q8Eng_n = I understand concepts I have studied in engineering

Q8Eng_o = Others ask me for help on engineering topics

Math Interest $\alpha=\mathbf{0 . 8 8}$

Q7Math_f = I am interested in learning more about MATH

Q7 Math _ $g=$ I enjoy learning MATH

Q7 Math _ $\mathrm{h}=$ I find fulfillment in doing MATH

Math Recognition $\alpha=\mathbf{0 . 8 6}$

Q7Math_b = My parents see me as a MATH person

Q7Math_c = My instructors see me as a MATH person

Q7Math_d = My peers see me as a MATH person

Q7Math_e = I've had experiences in which I was recognized as a MATH person

Q7Math_m = Others ask me for help in MATH

Math Performance/Competence $\alpha=0.90$

Q7Math_i = I am confident that I can understand MATH in class

Q7Math_j = I am confident that I can understand MATH outside of class

Q7Math_k = I can do well on exams in MATH

Q7Math_1 = I understand concepts I have studied in MATH

Q7Math_n = I can overcome setbacks in MATH 


\section{References}

1. Tonso K. The Impact of Cultural Norms on Women*. J Eng Educ. 1996; 217-225.

2. Wenger E. Communities of Practice and Social Learning Systems. Organization. 2000;7(2):225-246.

3. Holland D, Lachicotte W, Skinner D, Cain C. Identity and Agency in Cultural Worlds.; 1998.

4. Tonso KL. Student Engineers and Engineer Identity: Campus Engineer Identities as Figured World. Vol 1.; 2006. doi:10.1007/s11422-005-9009-2.

5. Varelas M. Identity Construction and Science Education Research Learning, Teaching, and Being in Multiple Contexts. Sense Publishers; 2012.

6. Carlone HB, Johnson A. Understanding the Science Experiences of Successful Women of Color: Science Identity as an Analytic Lens. J Res Sci Teach. 2007;44(8):1187-1218.

7. Jocuns A, Stevens R, Garrison L, Amos D. Students' changing images of engineering and engineers. In: Proceedings of the American Society for Engineering Education Annual Conference, Pittsburgh, PA. ; 2008:28.

8. Stevens R, O’Connor K, Garrison L, Jocuns A, Amo DM. Becoming an Engineer: Toward a Three Dimensional View of Engineering Learning. J Eng Educ. 2008;97(3):355-368.

9. Stevens R, O'Connor K, Garrison L. Engineering student identities in the navigation of the undergraduate curriculum. In: Association of the Society of Engineering Education Annual Conference. ; 2005:8.

10. Matusovich H, Streveler R, Miller R. Why do students choose engineering? A qualitative, longitudinal investigation of students' motivational values. J Eng Educ. 2010;99(4):289304.

11. Walden S, Foor C. "What's to keep you from dropping out?', Student Immigration into and within Engineering. J Eng Educ. 2008;97(2):191-205.

12. Foor CE, Walden SE, Trytten DA. I Wish that I Belonged More in this Whole Engineering Group: Achieving Individual Diversity. J Eng Educ. 2007.

13. Godwin A, Potvin G. Fostering Female Belongingness in Engineering through the Lens of Critical Engineering Agency. Int J Eng Educ. 2015;31(4):938-952.

14. Downey G, Lucena J. When students resist: Ethnography of a senior design experience in engineering education. Int J Eng Educ. 2003;19(1):168-176.

15. Tonso K. Teams that work: Campus culture, engineer identity, and social interactions. $J$ Eng Educ. 2006;95(1):25-37.

16. Fouad NA, Singh R, Fitzpatrick ME. Stemming the tide: Why women leave engineering. Univ Wisconsin-Milwaukee, Final Rep from NSF Award. 2011;827553.

17. Yoder BL. Engineering by the Numbers. Washington, D.C.; 2015.

18. National Science Foundation Arlington VA. Women, Minorities, and Persons with Disabilities in Science and Engineering: 2000. ERIC Clearinghouse; 2015.

19. Pascarella ET, Pierson CT, Wolniak GC, Terenzini PT. First-Generation College Students: Additional Evidence on College Experiences and Outcomes. J Higher Educ. 2004;75(3):249-284.

20. U.S. Department of Education. National Center for Education Statistics. Bridging the Gap: Academic Preparation and Postsecondary Success of First-Generation Students. Washington, D.C.; 2001.

21. Engle J, Bermeo A, O'Brien C. Straight from the source: What works for first-generation college students. Pell Inst Study Oppor. 2006. 
22. Saenz VB, Hurtado S, Barrera D, Wolf D, Yeung F. First in My Family: A Profile of First-Generation College Students at Four-Year Institutions Since 1971. Los Angeles; 2007.

23. Verdin D, Godwin A. Exploring Latina First-Generation College Students' Multiple Identities, Self-efficacy, and Institutional Integration to Inform Achievement in Engineering. J Women Minor Sci Eng. 2017.

24. Engle J. Postsecondary access and success for first-generation college students. Am Acad. 2007:25-48.

25. Defreitas SC, Rinn A. Academic achievement in first generation college students: The role of academic self-concept. J Scholarsh Teach Learn. 2013;13(1):57-67.

26. Martin JP, Miller MK, Simmons DR. Exploring the Theoretical Social Capital "Deficit" of First Generation College Students: Implications for Engineering Education. Int J Eng Educ. 2014;30(4):1-16.

27. Engle J, Tinto V. Moving beyond Access: College Success for Low-Income, FirstGeneration Students. Washington, D.C.; 2008.

28. Dika SL, D'Amico MM. Early experiences and integration in the persistence of firstgeneration college students in STEM and non-STEM majors. J Res Sci Teach. 2015;53(3):368-383.

29. Smith JM, Lucena JC. Invisible innovators: how low-income, first-generation students use their funds of knowledge to belong in engineering. Eng Stud. 2016;8629(March):1-26.

30. Raque-Bogdan TL, Lucas MS. Career Aspirations and the First Generation Student: Unraveling the Layers With Social Cognitive Career Theory. J Coll Stud Dev. 2016;57(3):248-262.

31. Fernandez MJ, Trenor JM, Zerda KS, Cortes C. First generation college students in engineering: A qualitative investigation of barriers to academic plans. Proc - Front Educ Conf FIE. 2008:1-5.

32. Verdin D, Godwin A. First in the Family: A Comparison of First-Generation and NonFirst-Generation Engineering College Students. Front Educ Conf. 2015:1-8.

33. Gee JP. Identity as an Analytic Lens for Research in Education. In: Secada WG, ed. Review of Research in Education. Vol 25. Washington, D.C.; 2001:99-126.

34. Brown BA. Discursive identity: Assimilation into the culture of science and its implications for minority students. J Res Sci Teach. 2004;41(8):810-834.

35. Hazari Z, Sonnert G, Sadler PM, Shanahan M-CC. Connecting high school physics experiences, outcome expectations, physics identity, and physics career choice: A gender study. J Res Sci Teaching. 2010;47(8):978-1003.

36. Potvin G, Hazari Z. The Development and Measurement of Identity across the Physical Sciences. In: Physics Educatoin Research Conference.; 2013:281-284.

37. Cass CP, Hazari Z, Cribbs J, Sadler PM, Sonnert G. Examining the impact of mathematics identity on the choice of engineering careers for male and female students. Proc Front Educ Conf. 2011:1-5.

38. Cribbs JD, Hazari Z, Sonnert G, Sadler PM. Establishing an explanatory model for Mathematics Identity. Child Dev. 2015;86(4):1048-1062.

39. Klotz L, Potvin G, Godwin A, Cribbs J, Hazari Z, Barclay N. Sustainability as a route to broadening participation in engineering. J Eng Educ. 2014;103(1):137-153.

40. Godwin A, Potvin G, Hazari Z, Lock R. Identity, Critical Agency, and Engineering: An Affective Model for Predicting Engineering as a Career Choice. J Eng Educ. 2016;105(2). 
41. Godwin A. The Development of a Measure of Engineering Identity. Proc from ASEE 2016 Am Soc Eng Educ Annu Conf Expo. 2016:15.

42. Kirn A, Godwin A, Benson L, et al. Intersectionality of Non-normative Identities in the Cultures of Engineering (InIce). Proc 123rd ASEE Annu Conf Expo. 2016:abstract accepted, final paper due Feb. 1, 2016. doi:10.18260/p.25448.

43. Welch BL. Significance of the Difference between Two Means when the Population Variances are unequal. Biometrika. 1938;29(3/4):350-362. doi:10.1038/187438a0.

44. Moser B, Stevens G. Homogeneity of variance in the two-sample means test. Am Stat. 1992;46(1):19-21.

45. Cohen J, Cohen P, West SG, Aiken LS. Applied Multiple Regression/correlation Analysis for the Behavioral Sciences. Lawrence Erlbaum Associates; 2003.

46. R Core Team. R: A Language and Environment for Statistical Computing. 2014.

47. Deci EL. The Relation of Interest to the Motivation of Behaviour: A Self-Determination Theory Perspective. In: Renninger A, Hidi S, Krapp A, eds. The Role of Interest in Learning and Development. Hillsdale, NJ: Erlbaum; 1992:43-70.

48. Basu SJ, Calabrese Barton A. Developing a Sustained Interest in Science among Urban Minority Youth. J Res Sci Teach. 2007;44(9):1269-1291. doi:10.1002/tea.

49. Geisinger BN, Raman DR a J. Why They Leave : Understanding Student Attrition from Engineering Majors. Int J Eng Educ. 2013;29(4):914-925.

50. Seymour E. "The Problem Iceberg" in science, mathematics, and engineering education: Student explanations for high attrition rates. J Coll Student Teach. 1992;21(4):230-238+.

51. Brainard SG, Carlin L. A Six-Year Longitudinal Study of Undergraduate Women in Engineering and Science *. 1998;1996(97).

52. Lent RW, Brown SD, Schmidt J, Brenner B, Lyons H, Treistman D. Relation of contextual supports and barriers to choice behavior in engineering majors: Test of alternative social cognitive models. J Couns Psychol. 2003;50(4):458-465.

53. Schaefers KG, Epperson DL, Nauta MM. Women's career development: Can theoretically derived variables predict persistence in engineering majors? J Couns Psychol. 1997;44(2):173-183.

54. Mejia JA, Wilson AA. Funds of Knowledge in Hispanic Students ' Communities and Households that Enhance Engineering Design Thinking. 2014.

55. Verdin D, Godwin A, Capobianco B. Systematic Review of the Funds of Knowledge Framework in STEM Education. In: American Society for Engineering Education (ASEE) Annual International Conference.; 2015.

56. Hazari Z, Brewe E, Goertzen RM, Hodapp T. The Importance of High School Physics Teachers for Female Students’ Physics Identity and Persistence. Teach. 2017;55(55).

57. Oyserman D. Identity-Based Motivation. Emerg trends Soc Behav Sci An Interdiscip searchable, linkable Resour. 2015.

58. Kirn A, Benson L. Engineering Students' Perceptions of the Future: Exploratory Instrument Development. In: American Society for Engineering Education Annual Conference \& Exposition. Seattle, WA; 2015:14.

59. Kirn A, Benson L. Engineering Students' Perceptions of Problem Solving and their Future. J Eng Educ. 